\title{
Relação entre a tributação do lucro e a estrutura de capital das grandes empresas no Brasil
}

\section{The relationship between the income taxation and the capital structure of large companies in Brazil}

\author{
Marcelo Coletto Pohlmann \\ Professor Adjunto da Faculdade de Administração, Contabilidade e Economia da Pontifícia \\ Universidade Católica do
}

\section{Sérgio De Iudícibus}

Professor do Curso de Ciências Contábeis e Financeiras da Pontifícia Universidade Católica de São Paulo e Professor Emérito da Faculdade de Economia, Administração e Contabilidade da Universidade de São Paulo*E-mail: siudicibus@osite.com.br

Recebido em 02.06.2010 * Aceito em 20.07.2010 * $2^{\mathrm{a}}$ versão aceita em 13.08.2010

\section{RESUMO}

O presente trabalho é uma pesquisa teórico-empírica que utiliza a análise de regressão linear múltipla com o objetivo de testar a validade de hipóteses relacionadas à influência da tributação do lucro na estrutura de capital das grandes empresas no Brasil. Segundo a teoria do tradeoff, a empresa, incentivada pela vantagem fiscal do endividamento, recorre a capitais de terceiros até o nível em que os custos associados aos riscos de falência superam essa vantagem. A teoria do pecking order, por sua vez, preconiza uma hierarquização das fontes de financiamento e não atribui à tributação do lucro papel relevante na explicação do endividamento. Duas hipóteses foram postas à prova: a primeira testou a validade da teoria do tradeoff quanto à existência de impacto da tributação do lucro no endividamento. A testou a presença dessa relação nas firmas com alto endividamento e baixo nível de tributação, para as quais não haveria a vantagem fiscal do endividamento. A pesquisa tomou por base valores médios dos dados de 2001 a 2003 das 500 maiores empresas estabelecidas no Brasil, segundo a Revista Exame. A hipótese central da pesquisa restou confirmada: existe uma relação positiva entre o nível de tributação do lucro e o grau de endividamento. Essa relação foi verificada, também, para as empresas com alto endividamento e baixo nível de tributação do lucro. Esses achados confirmaram o maior poder preditivo da teoria do tradeoff em detrimento da teoria do pecking order quanto ao impacto da tributação do lucro sobre a decisão de endividamento.

Palavras-chave: Estrutura de Capital. Endividamento. Tributação. Planejamento Tributário. Imposto de Renda.

\section{ABSTRACT}

This paper is an empirical research that uses analysis of multiple linear regression to test validity of hypotheses related to influence of profit taxation in capital structure of large companies in Brazil. According to the tradeoff theory, encouraged by tax advantage of debt, company appeals to third parties capitals up to the level in which costs related to bankruptcy risks overcome such advantage. Pecking order theory states a hierarchy of financing sources and does not attribute to profit taxation a relevant role in debt explanation. Two hypotheses were submitted to prove: the first one tested validity of tradeoff theory regarding impact of 
profit taxation in debt. Second hypothesis tested the presence of such relation in the companies with high debt and low taxation level, there are no tax advantage of debt for them. Research was based on average data for the years between 2001 and 2003 of the largest companies based in Brazil according to Revista Exame (Exame Magazine). The main hypothesis of the research was confirmed: there is a positive relation between the profit taxation level and the degree of leverage. Such relation was also verified for companies with high debt and low profit taxation level. Those findings confirmed the highest predictive power of tradeoff theory in detriment of pecking order theory concerning impact of profit taxation on capital structure decision.

Keywords: Capital structure. Leverage. Taxation. Tax planning. Income Tax.

\section{INTRODUÇÃO}

A identificação dos fatores determinantes da estrutura de capital tem sido uma busca constante por parte de pesquisadores da área das finanças corporativas. Duas teorias destacam-se no propósito de explicar o fenômeno: a teoria do tradeoff e a teoria do pecking order. Ambas as teorias têm sido constantemente submetidas a testes mediante estudos teórico-empíricos, mas os resultados inconsistentes não permitem concluir quanto ao maior poder explicativo de uma em relação à outra.

A relevância acadêmica do tema evidencia-se pelo número expressivo de pesquisas produzidas com o objetivo de explicar as escolhas das firmas quanto à estrutura de capital. Essa relevância nada mais é do que uma decorrência da importância da questão para a gestão financeira corporativa, pois as decisões de endividamento têm potencial impacto no valor econômico da firma.

Diversamente da teoria do pecking order, que não atribui relevância à variável tributária em seu modelo, a teoria do tradeoff preconiza que a estrutura de capital da firma é afetada, em algum grau, pelos níveis de tributação sobre o lucro. Segundo essa teoria, a expectativa é que quanto maior for a tributação do lucro, maior será o nível de endividamento, tendo em vista o incentivo decorrente da dedutibilidade dos juros da base de cálculo dos tributos incidentes sobre o lucro.

Hipóteses formuladas a partir da teoria do tradeoff foram testadas e confirmadas por estudos anteriores realizados em outros países (AYRES et al., 2001; BRIGHAM; HOUSTON, 1999; BURGMAN, 1996; CALEGARI, 2000; CLOYD et al., 1997; ELY et al., 2002; GROPP, 2002; GUENTHER, 1996; HARWOOD; MANZON, 2000; MILLS; NEWBERRY, 2004; MOHAMAD, 1995; MYERS, 2001; PILOTTE, 1990; SHIH, 1996; 
SMITH, 1997). Esses autores encontraram resultados preconizados pela teoria do tradeoff, que indicam uma relação positiva entre o nível de endividamento e o fator tributação do lucro.

Embora em número menor, alguns autores estrangeiros não encontraram, em relação ao fator tributação, resultados consistentes com a teoria do tradeoff (KRISHNAN; MOYER, 1996; JORGE; ARMADA, 1999; OOI, 1999).

No Brasil, há alguns estudos testando o impacto da variável tributação na estrutura de capital das firmas. Apresentando resultados consistentes com a teoria do tradeoff, podem ser citados os trabalhos de Nakamura et al. (2004) e Zani e Ness Júnior (2000). Diversamente, Futema et al. (2009), Bastos e Nakamura (2009) e Terra (2002) obtiveram resultados em desacordo com teoria do tradeoff quanto à tributação do lucro.

Uma possível explicação para os resultados inesperados na relação entre endividamento e tributação seria a presença, nas amostras, de firmas descapitalizadas, que não dispõem de outras fontes de financiamento além do capital de terceiros. Nesse caso, a firma não teria alternativa senão recorrer ao endividamento, mesmo na ausência de incentivo tributário para tanto.

Para empresas com essas características, poder-se-ia admitir maior poder preditivo à teoria do pecking order, que considera haver uma hierarquização das fontes de financiamento, enquanto a teoria do tradeoff atribui maior relevância à vantagem fiscal do endividamento.

Dadas essas considerações, busca-se responder às seguintes questões:

- O nível de tributação do lucro da firma afeta a decisão de estrutura de capital na forma preconizada pela teoria do tradeoff?

- Caso afirmativo, essa relação é válida e consistente mesmo para firmas que estejam sujeitas a baixos níveis de tributação do lucro, para as quais não há o incentivo tributário ao endividamento?

No cenário brasileiro, há peculiaridades potencialmente capazes de afetar as escolhas das firmas que justificam a utilidade de uma limitação da investigação empírica ao âmbito nacional. Primeiramente, os dividendos não são tributados quando distribuídos aos sócios ou acionistas. Isso representa um estímulo à utilização de capital próprio, uma vez que a remuneração é livre de impostos.

A segunda peculiaridade é a permissão legal de calcular, contabilizar e pagar Juros sobre o Capital Próprio (JCP), apurado mediante a aplicação de uma taxa de juros de longo prazo estabelecida pelo governo sobre as contas do patrimônio líquido da empresa. Os JCP são dedutíveis para fins de apuração dos tributos sobre o lucro e são tributados, na pessoa 
física, à alíquota de 15\%. Esses dois fatores podem levar a uma decisão de estrutura de capital diversa daquela que seria tomada caso eles não estivessem presentes.

Outra peculiaridade diz respeito ao mercado de crédito brasileiro, que se caracteriza por prazos mais curtos em que são feitos os financiamentos e o tipo de proteção mais usual entre os bancos para empréstimos privados, os quais se estendem para a emissão de títulos de dívida diretamente pelas empresas (debêntures e commercial papers). Os mecanismos de financiamento de longo prazo restringem-se aos bancos oficiais e a emissões de títulos desintermediados ainda sem expressão no total do mercado de financiamento brasileiro. A previsão do cenário futuro, nessas condições, não é factível para os banqueiros, que preferem efetuar operações de curto prazo (COELHO; LOPES, 2007).

Nakamura et al. (2004) asseveram que o mercado de capitais brasileiro tem dificuldade de crescer e atingir uma situação parecida com a de outros países mais desenvolvidos, por conta de uma forte concentração de investimentos no curto prazo, da inexistência de um mercado robusto de títulos de renda fixa de longo prazo e da presença de condições institucionais e econômicas desfavoráveis para abertura de capital.

O objetivo do estudo é, portanto, investigar a influência que o fator tributação do lucro exerce sobre a decisão de estrutura de capital das grandes empresas estabelecidas no Brasil à luz dos modelos preconizados pelas teorias do tradeoff e do pecking order. Trata-se de uma pesquisa teórico-empírica, em que são testadas hipóteses utilizando a análise de regressão linear múltipla.

Inicialmente, são apresentados os principais elementos caracterizadores das teorias do tradeoff e do pecking order, bem como as peculiaridades da tributação do lucro das empresas no Brasil. Após, delimita-se o problema, formulam-se as hipóteses de pesquisa e são demonstrados os procedimentos metodológicos. Seguem-se a análise dos resultados e a conclusão do estudo.

\section{REFERENCIAL TEÓRICO}

\subsection{Teorias sobre Estrutura de Capital}

A proposição da irrelevância da alavancagem para o valor da firma em um mercado perfeito e sem impostos, por Modigliani e Miller (1958), estabeleceu a base da moderna teoria da estrutura de capital ao definir uma heurística passível de adaptação a outras condições. Após, com a introdução da possibilidade de dedução tributária dos serviços da dívida, os mesmos autores (1963) demonstraram que o valor da firma depende linearmente do seu nível 
de endividamento, indicando que as empresas deveriam apresentar o maior grau de alavancagem possível (BRITO; LIMA, 2004).

Desde então, a teoria da estrutura de capital é um dos temas mais abordados nas pesquisas sobre Finanças e Contabilidade. A despeito da quantidade de estudos já realizados, uma questão ainda permanece aberta: existe uma estrutura ótima de capital? Em caso afirmativo, o que determina essa estrutura (KAYO et al., 2004)?

Weston e Brigham (2000), falando sobre estrutura-alvo de capital, afirmam que a política de estrutura de capital envolve a troca (tradeoff) entre risco e retorno: a utilização de mais dívida eleva o fator risco da corrente de ganhos da empresa, porém um índice mais alto de endividamento, geralmente, leva a uma taxa de retorno esperada mais alta. $\mathrm{O}$ risco mais alto associado à dívida maior tende a reduzir o preço das ações, mas a taxa de retorno esperada mais alta eleva esse preço. Portanto, sob a perspectiva da teoria do tradeoff, a estrutura ótima de capital é aquela que faz com que haja um equilíbrio entre risco e retorno para maximizar o preço das ações.

Do ponto de vista teórico e com base na pesquisa empírica, Ross, Jaffe e Westerfield (2009) apresentam quatro fatores importantes na determinação final de um índice desejado de endividamento:

- Impostos: Se uma empresa tiver (e for continuar tendo) lucro tributável, a utilização de mais capital de terceiros reduzirá os impostos devidos pela empresa e aumentará os impostos pagos por alguns titulares de suas obrigações.

- Tipos de ativos: Os custos de dificuldades financeiras dependem dos ativos que a empresa possui. Por exemplo, se uma empresa tiver um investimento substancial em terrenos, prédios e outros ativos tangíveis, seus custos de dificuldades financeiras serão menores do que uma empresa com investimentos grandes em pesquisa e desenvolvimento, que, geralmente, possuem um valor menor de revenda.

- Grau de incerteza do resultado operacional: As empresas com resultados operacionais incertos apresentam elevada probabilidade de dificuldades financeiras, mesmo sem dívidas, portanto, essas empresas são financiadas, basicamente, com capital próprio.

- Hierarquização de fontes e folga financeira: As empresas preferem usar capital próprio interno (ou seja, lucros retidos) a usar financiamento externo. No caso em que as necessidades de financiamento superem os lucros retidos, o endividamento é preferível à emissão de ações. Essa é a premissa crucial da teoria da hierarquização de fontes (pecking order theory). 
Jensen e Mekling (1976) introduziram os custos de agência na teoria do tradeoff ao observarem os conflitos de interesses inerentes à divisão da firma em obrigações e direitos assimétricos entre acionistas, gerentes e credores. O conflito entre acionistas e gestor surge quando o gestor não detém a totalidade das ações da empresa. Como o gestor não captura todo o crescimento dos lucros causado pelo seu esforço adicional, mas arca com a sua integridade, seu nível de empenho pode diferir do ótimo. Já o conflito entre acionistas e credores emerge em situações de insolvência. A responsabilidade limitada incentiva os acionistas de firmas insolventes, mas com fluxos de caixas livres, a investirem em projetos arriscados, mesmo que com valor presente líquido esperado negativo, uma vez que desfrutarão dos ganhos do sucesso e repassarão aos credores os custos do fracasso (BRITO; LIMA, 2004).

O modelo do pecking order de Myers (1984) descreve uma situação na qual, sob informação assimétrica entre gerentes e agentes externos, os custos de financiamento por terceiros extrapolam qualquer benefício. Para minimizar distorções, estabelece-se uma hierarquia das formas de financiamento que minimiza o custo da informação assimétrica. Visto que negócios mais rentáveis têm a opção de utilizar recursos internos, o modelo prevê menor endividamento para empresas mais lucrativas, contrário ao previsto pela teoria do tradeoff. Também em discordância com a teoria do tradeoff, a pecking order sugere uma relação positiva entre oportunidades de investimento e endividamento, posto que o nível de dívidas é determinado pelas diferenças acumuladas entre investimentos e lucros retidos. Finalmente, firmas com fluxos de caixa menos arriscados podem endividar-se mais, pois são menores as chances de terem que emitir títulos arriscados ou cancelarem investimentos promissores (BRITO; LIMA, 2004).

A literatura sobre a estrutura de capital é extensa, sendo que os principais fatores apontados pelos autores como potenciais determinantes do endividamento são sintetizados no Quadro 1.

Quadro 1: Fatores determinantes do endividamento

\begin{tabular}{|l|l|l|}
\hline n. & Fator & \multicolumn{1}{c|}{ Descrição } \\
\hline 1 & Setor & $\begin{array}{l}\text { As características idiossincráticas de cada setor, tais como tipo de atividade e grau de } \\
\text { concentração, afetariam as políticas de endividamento. Firmas de setores industriais e de } \\
\text { serviços ou de setores com maior grau de concentração, tendem a apresentar maior } \\
\text { endividamento, especialmente o de longo prazo. }\end{array}$ \\
\hline 2 & Lucratividade & Segundo a teoria do pecking order, firmas com maiores índices de lucratividade e/ou \\
\hline
\end{tabular}




\begin{tabular}{|c|c|c|}
\hline & e/ou retorno & $\begin{array}{l}\text { retorno tendem a utilizar menos recursos de terceiros no financiamento de suas atividades. } \\
\text { Na visão da teoria do tradeoff, dá-se o inverso. }\end{array}$ \\
\hline 3 & Tribu & $\begin{array}{l}\text { Firmas com mais altas cargas de tributação tendem a recorrer ao endividamento em } \\
\text { função do incentivo da dedutibilidade dos juros para fins de apuração dos tributos } \\
\text { incidentes sobre o lucro. }\end{array}$ \\
\hline 4 & $\begin{array}{l}\text { Estrutura de } \\
\text { ativos }\end{array}$ & $\begin{array}{l}\text { Firmas com maior proporção de ativos tangíveis que podem ser oferecidos como garantia } \\
\text { em empréstimos apresentam um endividamento maior. Firmas com alta proporção de } \\
\text { ativos específicos e/ou intangíveis tendem a apresentar endividamento menor. }\end{array}$ \\
\hline 5 & $\begin{array}{l}\text { Risco } \\
\text { empresarial }\end{array}$ & nto. \\
\hline 6 & Cres & $\begin{array}{l}\text { Segundo a teoria do pecking order, firmas com mais altos níveis de crescimento } \\
\text { apresentariam maior endividamento. Na visão da teoria do tradeoff, dá-se o inverso. }\end{array}$ \\
\hline 7 & $\begin{array}{l}\text { Tamanho da } \\
\text { firma }\end{array}$ & $\begin{array}{l}\text { A expectativa é que empresas de maior porte, por terem mais acesso a empréstimos em } \\
\text { melhores condições, apresentariam maior endividamento. }\end{array}$ \\
\hline 8 & $\begin{array}{l}\text { Tipo de } \\
\text { controle }\end{array}$ & $\begin{array}{l}\text { Características relacionadas ao controle da firma (se privado, estrangeiro, ou do governo) } \\
\text { afetariam o endividamento. Empresas estatais estariam sujeitas a menores riscos de } \\
\text { quebra e, por essa razão, teriam menores restrições ao endividamento. }\end{array}$ \\
\hline 9 & Grupo & $\begin{array}{l}\text { O fato de a firma pertencer a um grupo empresarial teria influências na estrutura de } \\
\text { capital. Firmas que pertencem a um grupo empresarial tendem a apresentar menores } \\
\text { índices de endividamento (PIGA, 2002). }\end{array}$ \\
\hline 10 & $\begin{array}{l}\text { Ações em } \\
\text { bolsa }\end{array}$ & $\begin{array}{l}\text { Empresas com ações negociadas na Bolsa de Valores teriam um incentivo maior ao } \\
\text { endividamento como forma de aumentar o valor de mercado de suas ações. }\end{array}$ \\
\hline
\end{tabular}

\subsection{A Tributação do Lucro no Brasil}

É oportuno esclarecer o nível de tributação teórico a que está sujeito o lucro das firmas brasileiras. Como regra geral, a alíquota do Imposto de Renda das Pessoas Jurídicas (IRPJ) é de $15 \%$, mais um adicional de $10 \%$ sobre o lucro anual que exceder a $\mathrm{R} \$ 240$ mil, ou $\mathrm{R} \$ 60$ mil, se a empresa optar pela apuração trimestral do imposto. Já a Contribuição Social sobre o Lucro Líquido (CSLL) tem uma alíquota de $9 \%$ sobre o lucro. Na sistemática de apuração denominada de Lucro Real, obrigatória para certas atividades e para as empresas de maior porte, as bases de cálculo do IRPJ e da CSLL são apuradas a partir do resultado contábil, sobre o qual são feitos ajustes (adições, exclusões e compensações).

Dessa forma, somando-se ambos os tributos, tem-se uma alíquota teórica máxima de 34\% (ou, mais precisamente, 33,99\%) sobre o lucro tributável, que, na maioria das vezes, não coincide com o lucro contábil devido aos ajustes decorrentes de legislação tributária, relativos 
a despesas não dedutíveis, receitas não tributáveis e prejuízos fiscais acumulados. O esquema básico de apuração da sistemática do Lucro Real é demonstrado no Quadro 2.

\section{Quadro 2: Esquema básico de apuração do Lucro Real}

Lucro líquido do exercício antes do IRPJ e da CSLL e após as participações

(+) Ajustes do Lucro Líquido

Adições

(-) Exclusões

(-) Compensações de prejuízos fiscais acumulados

$=$ Lucro Real

Fonte: Adaptado pelo autor com base na legislação do IRPJ e da CSLL.

Esclareça-se que, em função desses ajustes do lucro líquido para fins de apuração da base de cálculo dos tributos, podem surgir situações em que os valores contabilizados como despesas com IRPJ e CSLL não coincidam com a alíquota média esperada. A explicação para esse fato é que muitas empresas apresentam elevados valores relativos a despesas não dedutíveis ou a receitas não tributáveis para fins de apuração dos tributos sobre o lucro.

Essa sistemática de apuração dos tributos sobre o lucro tem o potencial de acarretar uma discrepância entre o valor dos tributos reportados na Demonstração do Resultado do Exercício (DRE) da empresa e o valor dos tributos que efetivamente devem ser por ela recolhidos relativo ao lucro tributável do período.

Esse aspecto deve ser levado em conta no delineamento da pesquisa, de modo a evitar que eventual diferença entre a tributação efetiva e a tributação reconhecida na DRE segundo o regime de competência não distorça os resultados dos testes empíricos.

\section{PROBLEMA E HIPÓTESES DE PESQUISA}

À luz da teoria do tradeoff, um dos principais fatores que incentiva o uso de capitais de terceiros é a possibilidade de dedução dos juros do lucro tributável, sendo que essa prática levaria à valorização da empresa pelo mercado. Assim, empresas altamente tributadas devem utilizar capitais de terceiros; empresas com baixa tributação não teriam o incentivo fiscal para recorrer ao endividamento.

Diante disso, questiona-se: uma firma que não dispõe de recursos internos para financiar suas atividades, deixará de recorrer ao uso de endividamento porque sua alíquota marginal atual dos tributos sobre o lucro é nula? A resposta parece lógica e não depende de maiores 
evidência empíricas, bastando considerar a premissa da racionalidade do agente; é, na verdade, uma questão de sobrevivência da empresa. É de se esperar que qualquer estudo empírico venha a encontrar firmas com tais características, especialmente aquelas com alto nível de endividamento e tributação nula. Por tal razão, esses aspectos devem ser levados em conta no delineamento da pesquisa.

Duas hipóteses são formuladas para teste. A primeira hipótese, seguindo os passos de estudos anteriores, busca pura e simplesmente verificar a existência de impacto do fator tributação do lucro no endividamento da firma e qual o sentido dessa influência:

Hipótese nula $\left(\mathrm{H}_{1}\right)$ : não existe relação entre o nível de tributação do lucro e o endividamento da firma.

Hipótese alternativa $\left(\mathrm{H}_{1}\right)$ : existe relação entre o nível de tributação do lucro e o endividamento da firma e essa relação é positiva.

Concomitantemente, testa-se a segunda hipótese com o fim de verificar como se dá a relação para o caso de firmas com alto endividamento e baixo nível de tributação:

Hipótese nula $\left(\mathrm{H}_{2}\right)$ : existe relação positiva entre o nível de tributação do lucro e o endividamento, mesmo para firmas com alto endividamento e tributação baixa ou inexistente.

Hipótese alternativa $\left(\mathrm{H}_{2}\right)$ : para o caso de firmas com alto endividamento e tributação do lucro baixa ou inexistente, não existe relação entre o nível de tributação e o endividamento.

\section{DELINEAMENTO METODOLÓGICO}

O objetivo do trabalho empírico desenvolvido é verificar a existência de relação entre variáveis; no presente caso, tem-se a variável dependente "endividamento" e a variável independente "tributação do lucro". Juntamente com essa última, outras variáveis apontadas pela literatura como explicativas do endividamento também serão consideradas.

Nessas circunstâncias, uma técnica estatística recomendada e uma das mais utilizadas na pesquisa acadêmica é a regressão linear múltipla, que provê um modelo explanatório da relação entre uma variável dependente e um conjunto de variáveis independentes.

Ressalte-se, por oportuno, que será preservada a nomenclatura vigente antes das alterações promovidas pelas leis 11.638/07 e 11.941/09 na Lei 6.404/76, uma vez que os dados se referem a período anterior a essas alterações e não há qualquer influência desse aspecto sobre os resultados da pesquisa. 
O endividamento, variável dependente, é analisado em três dimensões:

A) Endividamento geral (EG): soma do passivo circulante, incluindo-se as duplicatas descontadas, com o exigível a longo prazo, dividida pelo ativo total ajustado pelos efeitos da inflação, expresso em termos percentuais.

B) Endividamento de curto prazo (EC): soma do passivo circulante, incluindo-se as duplicatas descontadas, dividida pelo ativo total ajustado pelos efeitos da inflação, expresso em termos percentuais.

C) Endividamento de longo prazo (EL): soma do passivo exigível a longo prazo, dividida pelo ativo total ajustado pelos efeitos da inflação, expresso em termos percentuais.

Inicialmente, os fatores determinantes incluídos no teste são os seguintes:

A) Tributação do lucro (TR): é o percentual obtido pela divisão da soma do IRPJ e da CSLL pelo lucro líquido do exercício antes de considerados os efeitos desses mesmos tributos, expresso em termos percentuais.

B) Lucratividade (LU): é a margem de lucro sobre as vendas, ou seja, o lucro líquido do exercício, antes de deduzidos o IRPJ e a CSLL, dividido pelo montante das vendas brutas, expresso em termos percentuais.

C) Crescimento (CR): equivale ao crescimento das vendas do último ano sobre a média dos dois anos anteriores, expresso em termos percentuais.

D) Risco (RI): é o desvio-padrão do lucro líquido do exercício relativo ao período analisado.

E) Estrutura de ativos (GI): é medida pelo grau de imobilização do ativo, ou seja, o total do ativo permanente, ajustado pelos efeitos da inflação, dividido pelo ativo total ajustado, expresso em termos percentuais.

F) Tamanho da firma (TA): medido pelo valor do ativo total ajustado na data do encerramento do último exercício analisado.

G) Concentração do setor (CC): medido de acordo com a razão de concentração de ordem quatro, CR(4), índice que, segundo Resende e Boff (2002), mede o poder de mercado exercido pelas quatro maiores empresas do setor. O grau de concentração foi calculado somando-se os percentuais de participação das quatro maiores empresas de cada setor no último exercício analisado.

H) Setor (SE): variável dummy que indica o setor a que pertence cada firma da amostra, sendo igual a " 0 " se pertencente ao setor industrial ou de prestação de serviços e igual a " 1 " se empresa comercial. 
I) Controle (CO): para esse fator, foram criadas duas variáveis dummy. A primeira refere-se a controle nacional (“0”) ou estrangeiro (“1”); a segunda refere-se a controle nacional estatal ("1") ou privado ("0").

J) Grupo (GR): variável dummy que indica se a firma pertence a um grupo empresarial (“1”) ou não (“0”).

K) Negócios na Bolsa de Valores (BV): variável dummy que indica se a firma tem ações negociadas na Bolsa ("1") ou não ("0”).

A população estudada é composta por todas as empresas brasileiras. Dada a extrema dificuldade e o pouco efeito prático de adoção de um procedimento de amostragem aleatório, adota-se um procedimento intencional, que é aquele em que um grupo de elementos é escolhido intencionalmente pelo pesquisador para compor a amostra (MARTINS, 2001).

Para esse fim, recorre-se ao banco de dados e às edições da publicação "Exame Melhores e Maiores", onde são armazenadas informações referentes às quinhentas maiores empresas brasileiras segundo o critério do volume de vendas. Foram coletados os dados dos exercícios encerrados em 2001, 2002 e 2003, sendo que as informações relativas ao IRPJ e à CSLL foram obtidas diretamente com a entidade responsável pela referida publicação, já que não são divulgadas na edição anual da revista. Registre-se que a escolha do período de análise recaiu sobre os últimos três exercícios disponíveis por ocasião da realização dos testes empíricos. Esses, por sua vez, integraram tese de doutorado defendida no ano de 2005.

Assim, a amostra inicial, composta das 500 maiores empresas brasileiras não financeiras, foi reduzida para 405, tendo em vista a disponibilidade de dados relativos aos tributos incidentes sobre o lucro.

Uma questão que merece ser enfrentada, nesse momento, diz respeito à escolha de um período de três anos. Primeiramente, deve-se ressaltar que o teste das hipóteses de pesquisa poderia ser feito com base nos dados de apenas um exercício, em uma amostragem estritamente transversal (cross-sectional).

O problema dessa escolha é que as diferenças intertemporais poderiam distorcer a análise. Na sistemática de apuração do IRPJ e da CSLL, as peculiaridades de cada exercício podem modificar sensivelmente o valor dos tributos a recolher no período. Considerando que é a tributação efetiva que tem o potencial de impactar a decisão de estrutura de capital, os valores constantes da DRE podem não capturar essa grandeza, pois não estão atrelados ao regime de caixa, mas ao regime de competência. 
Isso ocorre com os prejuízos fiscais acumulados de períodos anteriores, em função dos quais a base de cálculo dos tributos pode ser reduzida em até $30 \%$. Segundo a teoria do tradeoff, a atratividade da dedutibilidade dos juros do endividamento para fins tributários fica reduzida ante a existência de prejuízos fiscais ou de outros valores que reduzem a tributação marginal do lucro da firma (Nondebt Tax Shields). Nesse caso, o IRPJ e a CSLL efetivamente recolhidos seriam, significativamente, inferiores aos valores reportados na DRE.

A amostra foi, ainda, depurada da seguinte forma: primeiramente, foram excluídas as firmas que não possuíam os dados relativos ao IRPJ, à CSLL e ao endividamento relativamente aos três exercícios, perfazendo um total de 88 empresas excluídas por esse motivo.

Foram excluídas da amostra, ainda, as firmas que apresentaram um prejuízo médio, mas com IRPJ e CSLL devidos. A razão para isso é que os números se tornam sem sentido e distorcem a análise, tanto para fins de regressão linear múltipla quanto para fins de análise cluster.

Isso fica claro no seguinte exemplo: uma empresa da amostra apresentou uma média de IRPJ e CSLL de US\$ 6,4 milhões e um prejuízo médio, antes do IRPJ e da CSLL, de US\$ 15,8 milhões, o que implica uma tributação média do resultado de 40,5\% negativo. É difícil explicar o significado desse percentual e certamente provocaria inconsistências nos resultados, razão pela qual foi excluído um total de 38 firmas.

Merece análise a situação em que o IRPJ e a CSLL, somados, apresentam um valor positivo; ou seja, são os casos das empresas que tiveram uma suposta "receita" com esses tributos. Uma solução inicial seria modificar o valor para zero, de forma que, para os fins da presente pesquisa, o mínimo admitido para a variável tributação seria igual a zero. Essa providência justifica-se, primeiramente, porque também seria um número sem sentido a relação entre um tributo positivo e o resultado, seja um lucro ou um prejuízo.

É o caso de uma firma da amostra que apresentou uma média de tributos positivos igual a US\$ 1,7 e um lucro antes dos tributos de US\$ 34,5, o que implica uma tributação média de 4,9\% positivo. O que significa esse número? Em termos práticos, essa empresa não teve a incidência dos tributos e isso é o que importa para fins do presente trabalho, mais especificamente para fins da decisão de endividamento.

Nessa hipótese, poder-se-ia assumir que a carga tributária da firma é igual a zero e seria evitada a exclusão desses casos, que não são poucos. Ocorre que, ao equiparar todos esses valores a zero, criar-se-ia um grande grupo de firmas com o mesmo valor para a variável 
tributação, o que representaria um grave risco de violação de normalidade exigida como pressuposto da aplicação da análise de regressão linear múltipla.

Dessa forma, sob pena de violação da premissa básica da distribuição normal exigida, outra solução não resta senão excluir essas observações da amostra, o que perfaz um total de 65 firmas eliminadas. Após esses procedimentos, restou uma amostra final de 214 empresas, com as características descritas na Tabela 1.

Tabela 1: Composição da amostra final

\begin{tabular}{|lr|lr|lr|rr|}
\hline \multicolumn{2}{|c|}{ Setor } & & \multicolumn{2}{|c|}{ Controle } & \multicolumn{2}{c|}{ Grupo empresarial } & \multicolumn{2}{c|}{$\begin{array}{c}\text { Ações negociadas em } \\
\text { bolsa }\end{array}$} \\
\hline Indústria & 113 & Privado nacional & 138 & Pertence & 148 & Sim & 60 \\
\hline Comércio & 42 & Estatal nacional & 16 & Não pertence & 66 & Não & 154 \\
\hline Serviços & 59 & Estrangeiro & 60 & & & 214 \\
\hline Total & 214 & Total & 214 & Total & 214 & Total \\
\hline
\end{tabular}

Os pressupostos básicos da análise de regressão múltipla foram atendidos, ou seja, a linearidade do fenômeno mensurado, a variância constante do termo do erro (homocedasticidade), a independência dos termos do erro e a normalidade da distribuição do erro. Quanto à normalidade das variáveis, depois de aplicado o teste Kolmogorov-Smirnov modificado (HAIR JR. et al., 1998), foi realizada uma transformação logarítmica para correção dos desvios, tendo-se obtido sucesso com as variáveis LU, RI e TA, enquanto a tentativa foi infrutífera com relação às variáveis CR e CC, razão pela qual essas últimas foram descartadas.

Antes de ir em frente, há que se enfrentar a questão das anomalias encontradas em pesquisas anteriores, relativas a resultados inconsistentes ou ambíguos quanto ao impacto da variável proxy da tributação sobre o nível de endividamento, havendo empresas com alto nível de tributação apresentando baixo endividamento e vice-versa. Convém verificar se essa circunstância está presente na amostra, especialmente a situação de tributação nula e endividamento elevado e, caso afirmativo, de que maneira o problema será contornado.

Processando-se uma análise de regressão múltipla incluindo todas as variáveis independentes, testadas em relação a cada uma das variáveis dependentes, e utilizando o método stepwise, em que somente os melhores modelos são hierarquizados e as variáveis não significativas são excluídas, verifica-se que a variável tributação apresenta relação positiva e significativa com o endividamento geral (EG) e de curto prazo (EC). Entretanto, com relação 
ao endividamento de longo prazo, a variável TR não se mostrou significativa e apresentou sinal negativo. Os coeficientes são mostrados na Tabela 2.

Tabela 2: Regressão linear preliminar: EG, EC e EL

\begin{tabular}{|c|c|c|c|c|}
\hline \multicolumn{5}{|c|}{$\begin{array}{l}\mathrm{EG}=B_{o}+B_{l} \mathrm{TR} \\
\mathrm{EC}=B_{o}+B_{I} \mathrm{TR} \\
\mathrm{EL}=B_{o}+B_{l} \mathrm{TR}\end{array}$} \\
\hline Variável dependente & $\begin{array}{c}\text { Variável } \\
\text { independente }\end{array}$ & Coeficiente beta & Valor $\mathrm{t}$ & Sig. \\
\hline EG & TR & 0,186 & 2,920 & 0,004 \\
\hline EC & TR & 0,186 & 3,022 & 0,003 \\
\hline EL & TR & $-0,054$ & $-0,767$ & 0,445 \\
\hline
\end{tabular}

$\mathrm{EG}=$ Endividamento geral.

$\mathrm{EC}=$ Endividamento de curto prazo.

$\mathrm{EL}=$ Endividamento de longo prazo.

TR = Tributação do lucro.

Isso indica a necessidade de alguma providência que corrija o problema, ainda que ele tenha sido detectado apenas com relação ao EL. Conforme discutido na subseção anterior, essa situação não pode ser considerada anômala, pois, de acordo com as proposições e implicações da teoria do pecking order, é de se esperar que existam empresas com endividamento elevado e tributação baixa ou inexistente.

Utilizando-se, simplesmente, a totalidade da amostra sem qualquer ajuste, ter-se-á uma inevitável distorção no resultado, uma vez que não se pode esperar uma perfeita linearidade no fenômeno.

Grande parte das empresas será incentivada ao endividamento em função da dedutibilidade dos juros, inclusive daqueles incluídos no preço das mercadorias adquiridas a prazo e não apenas os decorrentes de empréstimos.

Haverá, no entanto, empresas que não terão esse incentivo e, ainda assim, poderão necessitar de elevada proporção de capitais de terceiros. Assim, deve-se encontrar um meio de tratar essas empresas como se fossem amostras de outra população, tendo-se em vista os aspectos tributários da questão. Um procedimento possível e recomendado pela literatura 
(MARTINS, 2001; HAIR JR. et al., 1998; AAKER et al., 2001) é a utilização de uma variável dummy para contemplar o efeito dessa idiossincrasia.

Resta definir o procedimento por meio do qual será gerada essa variável dummy. Como identificar esse grupo de firmas sujeito a uma baixa tributação e com um alto nível de endividamento? De certo que não se trata de questão trivial e que possa ser adequadamente resolvida sem recorrer a alguma técnica que evite o viés do pesquisador. Nesses casos, a análise cluster é recomendada (HAIR JR. et al., 1998).

A partir de uma análise cluster utilizando as variáveis dependentes (EG, EC e EL), uma a uma, juntamente com a variável tributação (TR), e verificado, mediante uma análise da variância (ANOVA), que os grupos são significativamente diferentes quanto aos atributos endividamento e tributação, são criadas três novas variáveis dummy, que representarão os efeitos idiossincráticos dessas firmas com alto endividamento e tributação baixa ou nula. Para facilitar a identificação, os elementos integrantes desse grupo passam a ser chamados de "firmas descapitalizadas com alto endividamento":

A) Firmas descapitalizadas com alto endividamento geral (DEG): variável dummy de valor "0" para o cluster das firmas em geral e de valor " 1 " para o cluster das firmas com alto endividamento geral e baixa tributação.

B) Firmas descapitalizadas com alto endividamento de curto prazo (DEC): variável dummy de valor " 0 " para o cluster das firmas em geral e de valor " 1 " para o cluster das firmas com alto endividamento de curto prazo e baixa tributação.

C) Firmas descapitalizadas com alto endividamento de longo prazo (DEL): variável dummy de valor "0" para o cluster das firmas em geral e de valor "1" para o cluster das firmas com alto endividamento de longo prazo e baixa tributação.

Na Tabela 3, é apresentada a composição dos grupos resultantes da análise cluster. A amostra foi dividida em dois grupos: o que contém as firmas consideradas descapitalizadas, que apresentam alto endividamento e baixa tributação, e o que contém as demais firmas.

Tabela 3: Grupos resultantes da análise cluster

\begin{tabular}{|l|r|r|r|c|c|}
\hline \multicolumn{1}{|c|}{ Grupos } & Qtde. & $\begin{array}{r}\text { Endividamento } \\
\text { (média) }\end{array}$ & $\begin{array}{c}\text { TR } \\
\text { (média) }\end{array}$ & $\begin{array}{c}\text { Missing } \\
\text { Values }\end{array}$ & $\begin{array}{c}\text { Qtde. } \\
\text { Total }\end{array}$ \\
\hline DEG=0 & 202 & $49,7 \%$ & $21,9 \%$ & 6 & 214 \\
DEG=1 & 6 & $77,7 \%$ & $0,9 \%$ & & \\
\hline DEC $=0$ & 124 & $25,8 \%$ & $27,4 \%$ & 9 & 214 \\
\cline { 2 - 5 } & & & &
\end{tabular}




\begin{tabular}{|l|r|r|r|r|r|}
$\mathrm{DEC}=1$ & 81 & $34,8 \%$ & $11,7 \%$ & & \\
\hline $\mathrm{DEL}=0$ & 133 & $15,8 \%$ & $27,6 \%$ & 5 & 214 \\
$\mathrm{DEL}=1$ & 76 & $28,4 \%$ & $11,0 \%$ & & \\
\hline
\end{tabular}

O Quadro 3 contém a síntese de todos os fatores e as respectivas variáveis que serão utilizadas no teste das hipóteses de pesquisa.

\section{Quadro 3: Fatores e variáveis}

\begin{tabular}{|c|c|c|c|c|c|c|c|}
\hline $\mathrm{N}$. & Fator & Variável & Notação & Fórmula ou descrição & $\begin{array}{l}\mathrm{D} / \mathrm{I} \\
(1)\end{array}$ & Medida & $\begin{array}{r}\mathrm{C} / \mathrm{N} \\
(2)\end{array}$ \\
\hline \multirow[t]{3}{*}{1} & \multirow[t]{3}{*}{ Endividamento } & Endividamento geral & EG & $\begin{array}{l}(\mathrm{PC}+\mathrm{DD}+\mathrm{PELP}) \times 100 / \\
\mathrm{AT}^{\prime}\end{array}$ & $\mathrm{D}$ & $\%$ & $\mathrm{C}$ \\
\hline & & $\begin{array}{l}\text { Endividamento de curto } \\
\text { prazo }\end{array}$ & $\mathrm{EC}$ & $(\mathrm{PC}+\mathrm{DD}) \times 100 / \mathrm{AT}$ & $\mathrm{D}$ & $\%$ & $\mathrm{C}$ \\
\hline & & $\begin{array}{l}\text { Endividamento de longo } \\
\text { prazo }\end{array}$ & EL & PELP x $100 /$ AT' & $\mathrm{D}$ & $\%$ & $\mathrm{C}$ \\
\hline 2 & Tributação & Tributação do lucro & TR & $\begin{array}{l}(\text { IRPJ + CSLL) } \times 100 / \\
\text { LLEAIRCSLL }\end{array}$ & I & $\%$ & $\mathrm{C}$ \\
\hline 3 & Lucratividade & Lucratividade & LU & $\begin{array}{l}\text { LLEAIRCSLL x } 100 \text { / } \\
\text { Vendas }\end{array}$ & I & $\%$ & $\mathrm{C}$ \\
\hline 4 & Crescimento & Crescimento das vendas & CR & $\begin{array}{l}\text { Vendas } 2003 \times 100 / \\
\left(\left(\text { Vendas }^{2} 2001^{\prime}+\text { Vendas }\right.\right. \\
\left.\left.2002^{\prime}\right)\right) / 2\end{array}$ & I & $\%$ & $\mathrm{C}$ \\
\hline 5 & Risco & Risco & RI & Desvio-padrão do LLE & $\mathrm{I}$ & $\%$ & $\mathrm{C}$ \\
\hline 6 & $\begin{array}{l}\text { Estrutura de } \\
\text { ativos }\end{array}$ & $\begin{array}{l}\text { Grau de imobilização } \\
\text { dos ativos }\end{array}$ & GI & $\mathrm{AP}^{\prime} \times 100 / \mathrm{AT}$ & I & $\%$ & $\mathrm{C}$ \\
\hline 7 & $\begin{array}{l}\text { Tamanho da } \\
\text { firma }\end{array}$ & Tamanho da firma & TA & AT' & I & US\$ & $\mathrm{C}$ \\
\hline 8 & $\begin{array}{l}\text { Concentração } \\
\text { do setor }\end{array}$ & Concentração do setor & $\mathrm{CC}$ & $\begin{array}{l}\text { Índice de concentração } \\
\text { CR(4) }\end{array}$ & $\mathrm{I}$ & $\%$ & $\mathrm{C}$ \\
\hline 9 & Setor & Setor & SE & $\begin{array}{l}\text { (Indústria e serviços) ou } \\
\text { (comércio) }\end{array}$ & $\mathrm{I}$ & $0 / 1$ & $\mathrm{~N}$ \\
\hline 10 & Controle & Controle & $\mathrm{CO}^{\prime}$ & $\begin{array}{l}\text { (Nacional privado ou } \\
\text { estatal) ou (estrangeiro) }\end{array}$ & $\mathrm{I}$ & $0 / 1$ & $\mathrm{~N}$ \\
\hline
\end{tabular}




\begin{tabular}{|c|c|c|c|c|c|c|c|}
\hline & & & CO" & $\begin{array}{l}\text { (Privado nacional ou } \\
\text { estrangeiro) ou (estatal) }\end{array}$ & I & $0 / 1$ & $\mathrm{~N}$ \\
\hline 11 & Grupo & Grupo & GR & $\begin{array}{l}\text { (Não pertence a grupo } \\
\text { empresarial) ou (pertence) }\end{array}$ & I & $0 / 1$ & $\mathrm{~N}$ \\
\hline 12 & $\begin{array}{l}\text { Negócios na } \\
\text { Bolsa de } \\
\text { Valores }\end{array}$ & $\begin{array}{l}\text { Negócios } \mathrm{Na} \text { Bolsa De } \\
\text { Valores }\end{array}$ & $\mathrm{BV}$ & $\begin{array}{l}\text { (Não tem ações negociadas } \\
\text { na BV) ou (tem) }\end{array}$ & I & $0 / 1$ & $\mathrm{~N}$ \\
\hline \multirow[t]{3}{*}{13} & \multirow[t]{3}{*}{$\begin{array}{l}\text { Cluster } \\
\text { descapitalizado }\end{array}$} & $\begin{array}{l}\text { Cluster descapitalizado } \\
\text { do endividamento geral }\end{array}$ & DEG & $\begin{array}{l}\text { (Não pertence ao cluster) } \\
\text { ou (pertence) }\end{array}$ & I & $0 / 1$ & $\mathrm{~N}$ \\
\hline & & $\begin{array}{l}\text { Cluster descapitalizado } \\
\text { do endiv. curto prazo }\end{array}$ & DEC & $\begin{array}{l}\text { (Não pertence ao cluster) } \\
\text { ou (pertence) }\end{array}$ & I & $0 / 1$ & $\mathrm{~N}$ \\
\hline & & $\begin{array}{l}\text { Cluster descapitalizado } \\
\text { do endiv. longo prazo }\end{array}$ & DEL & $\begin{array}{l}\text { (Não pertence ao cluster) } \\
\text { ou (pertence) }\end{array}$ & I & $0 / 1$ & $\mathrm{~N}$ \\
\hline
\end{tabular}

(1) Variável dependente ou independente.

(2) Variável com nível de mensuração contínuo (C) ou nominal (N).

(3) O apóstrofo ('), ao lado da variável na fórmula matemática, indica que se trata de valor ajustado pelos efeitos da inflação.

Siglas: $\mathrm{PC}=$ Passivo circulante DD = Duplicatas descontadas; $\mathrm{PELP}=$ Passivo exigível a longo prazo; $\mathrm{AP}=$ Ativo permanente; AT = Ativo total $;$ LLE $=$ Lucro líquido do exercício; LLEAIRCSLL $=$ LLE antes do IRPJ e da CSLL.

Dessa forma, aquela parcela de endividamento adicional decorrente da condição de a firma pertencer a esse grupo que utiliza elevado montante de capitais de terceiros, apesar de não ter incentivo tributário para tanto, será representado pelo parâmetro assumido pela variável dummy.

\section{ANÁLISE DOS RESULTADOS}

De uma maneira geral, os achados da pesquisa confirmaram as expectativas. Os resultados das regressões são apresentados nas tabelas 4, 5 e 6, evidenciando relação significativa (coeficientes de significância iguais ou inferiores a 0,01) entre a variável dependente e as variáveis explicativas, dentre elas a tributação.

A Tabela 4 demonstra que o conjunto de variáveis independentes explica $29,7 \%$ da variação no endividamento geral, sendo que o modelo com quatro variáveis independentes foi o que melhor desempenho apresentou, o que é evidenciado pelo $\mathrm{R}^{2}$ ajustado maior do que os modelos com uma ou duas variáveis independentes. 
Tabela 4: Resultados da análise de regressão da variável dependente EG

\begin{tabular}{|c|c|c|c|c|c|c|c|c|}
\hline \multicolumn{9}{|c|}{$\mathrm{EG}=B_{o}+B_{l} \mathrm{LU}+B_{2} \mathrm{TA}+B_{3} \mathrm{TR}+B_{4} \mathrm{DEG}$} \\
\hline \multicolumn{2}{|c|}{ Correlações e ANOVA } & \multicolumn{7}{|c|}{ Variáveis incluídas no modelo } \\
\hline & & Variáveis & Coef. & Erro pad. & Coef. beta & $\mathrm{t}$ & Sig. & Tolerância \\
\hline $\mathrm{R}$ & 0,545 & Constante & 40,022 & 7,010 & & 5,709 & 0,000 & \\
\hline $\mathrm{R}^{2}$ & 0,297 & LU & $-8,583$ & 1,171 & $-0,513$ & $-7,329$ & 0,000 & 0,783 \\
\hline $\mathrm{R}^{2}$ ajust. & $0,282 *$ & TA & 3,223 & 1,167 & 0,195 & 2,761 & 0,006 & 0,770 \\
\hline Erro pad. & 16,326 & TR & 0,354 & 0,103 & 0,220 & 3,432 & 0,001 & 0,931 \\
\hline Durbin-W. & 1,864 & DEG & 25,065 & 9,854 & 0,163 & 2,544 & 0,012 & 0,930 \\
\hline $\mathrm{F}$ & 19,347 & & & & & & & \\
\hline Sig. & 0,000 & & & & & & & \\
\hline
\end{tabular}

$* \mathrm{R}^{2}$ ajustado superior àqueles dos dois modelos anteriores indicados pelo método stepwise.

$\mathrm{EG}=$ Endividamento geral $(\%)$.

LU = Lucratividade (margem de lucro sobre as vendas). Essa variável sofreu transformação logarítmica. Dessa forma, LU representa o logaritmo da margem de lucro sobre as vendas.

TA = Tamanho da firma (ativo total). Essa variável sofreu transformação logarítmica. Dessa forma, TA representa o logaritmo do valor do ativo total.

TR $=$ Tributação do lucro $(\%)$.

DEG = Variável dummy das firmas descapitalizadas com alto endividamento geral. $\mathrm{O}$ coeficiente $B_{4}$ pode assumir valor "1" (firmas descapitalizadas com alto endividamento) ou "0" (demais firmas).

A Tabela 5, por sua vez, evidencia que o conjunto de variáveis independentes explica $51,7 \%$ da variação no endividamento de curto prazo, sendo que o modelo com quatro variáveis independentes foi o de melhor desempenho, o que é evidenciado pelo $\mathrm{R}^{2}$ ajustado maior do que os modelos com menos variáveis independentes.

Tabela 5: Resultados da análise de regressão da variável dependente EC

\begin{tabular}{|c|c|c|c|c|c|c|c|c|}
\hline & & & $=B_{o}+B$ & $\mathrm{~J}+B_{2} \mathrm{DEC}$ & $B_{3} \mathrm{TR}+B$ & & & \\
\hline Correlaçõ & ANOVA & & & Variáve & incluídas & nodelo & & \\
\hline & & Variáveis & Coef. & Erro pad. & Coef. beta & $\mathrm{t}$ & Sig. & Tolerância \\
\hline $\mathrm{R}$ & 0,719 & Constante & 15,070 & 3,775 & & 3,991 & 0,000 & \\
\hline $\mathrm{R}^{2}$ & 0,517 & LU & $-3,883$ & 0,894 & $-0,271$ & $-4,344$ & 0,000 & 0,704 \\
\hline $\mathrm{R}^{2}$ ajust. & $0,506^{*}$ & DEC & 18,610 & 2,239 & 0,533 & 7,509 & 0,000 & 0,544 \\
\hline Erro pad. & 10,789 & TR & 0,665 & 0,089 & 0,523 & 7,477 & 0,000 & 0,561 \\
\hline
\end{tabular}




\begin{tabular}{|c|c|c|c|c|c|c|c|c|}
\hline Durbin-W. & 1,836 & SE & 7,631 & 2,307 & 0,197 & 3,308 & 0,001 & 0,775 \\
\hline $\mathrm{F}$ & 47,105 & & & & & & & \\
\hline Sig. & 0,000 & & & & & & & \\
\hline
\end{tabular}

$* \mathrm{R}^{2}$ ajustado superior àqueles dos dois modelos anteriores indicados pelo método stepwise.

$\mathrm{EC}=$ Endividamento de curto prazo $(\%)$.

LU = Lucratividade (margem de lucro sobre as vendas). Esta variável sofreu transformação logarítmica. Dessa forma, LU representa o logaritmo da margem de lucro sobre as vendas.

DEC = Variável dummy das firmas descapitalizadas com alto endividamento de curto prazo. $\mathrm{O}$ coeficiente $B_{2}$ pode assumir valor "1" (firmas descapitalizadas com alto endividamento) ou " 0 " (demais firmas).

TR $=$ Tributação do lucro $(\%)$.

$\mathrm{SE}=$ Setor (o coeficiente $B_{4}$ pode assumir valor " 1 " se a firma for pertencente ao setor comercial e valor " 0 " se pertencente aos setores industrial ou de serviços).

A Tabela 6, por fim, registra que o conjunto de variáveis independentes explica $39,8 \%$ da variação no endividamento de longo prazo, sendo que o modelo com cinco variáveis independentes mostrou-se superior, o que é evidenciado pelo $\mathrm{R}^{2}$ ajustado maior do que os modelos com menos variáveis independentes. $\mathrm{O}$ valor $\mathrm{F}$ confirma esse bom desempenho dos modelos, embora persista uma grande variação do endividamento atribuído a outros fatores não incluídos na equação final.

Tabela 6: Resultados da análise de regressão da variável dependente EL

\begin{tabular}{|c|c|c|c|c|c|c|c|c|}
\hline \multicolumn{9}{|c|}{$\mathrm{EL}=B_{o}+B_{1} \mathrm{DEL}+B_{2} \mathrm{TR}+B_{3} \mathrm{TA}+B_{4} \mathrm{LU}+B_{5} \mathrm{GI}$} \\
\hline \multicolumn{2}{|c|}{ Correlações e ANOVA } & \multicolumn{7}{|c|}{ Variáveis incluídas no modelo } \\
\hline & & Variáveis & Coef. & Erro pad. & Coef. beta & $\mathrm{t}$ & Sig. & Tolerância \\
\hline $\mathrm{R}$ & 0,631 & Constante & $-18,088$ & 5,079 & & $-3,703$ & 0,000 & \\
\hline $\mathrm{R}^{2}$ & 0,398 & DEL & 18,249 & 2,217 & 0,595 & 8,230 & 0,000 & 0,628 \\
\hline $\mathrm{R}^{2}$ ajust. & $0,382 *$ & TR & 0,521 & 0,085 & 0,444 & 6,147 & 0,000 & 0,631 \\
\hline Erro pad. & 11,435 & TA & 3,410 & 0,868 & 0,273 & 3,931 & 0,000 & 0,683 \\
\hline Durbin-W. & 1,878 & LU & $-2,507$ & 0,828 & $-0,198$ & $-3,028$ & 0,003 & 0,769 \\
\hline $\mathrm{F}$ & 24,219 & GI & 0,128 & 0,046 & 0,186 & 2,774 & 0,006 & 0,735 \\
\hline
\end{tabular}

$* \mathrm{R}^{2}$ ajustado superior àqueles dos dois modelos anteriores indicados pelo método stepwise.

$\mathrm{EL}=$ Endividamento de longo prazo $(\%)$.

DEL = Variável dummy das firmas descapitalizadas com alto endividamento de longo prazo. O coeficiente $B_{I}$ pode assumir valor "1" (firmas descapitalizadas com alto endividamento) ou " 0 " (demais firmas).

TR $=$ Tributação do lucro $(\%)$. 
TA = Tamanho da firma (ativo total). Essa variável sofreu transformação logarítmica. Dessa forma, TA representa o logaritmo do valor do ativo total.

LU = Lucratividade (margem de lucro sobre as vendas). Essa variável sofreu transformação logarítmica. Dessa forma, LU representa o logaritmo da margem de lucro sobre as vendas.

GI = Grau de imobilização do ativo (\%).

Ao lado da lucratividade, o fator tributação apareceu com grande destaque na explicação dos níveis de endividamento. Isso responde afirmativamente a uma das indagações clássicas da teoria das finanças: o endividamento aumenta o valor da empresa? Assim, as empresas que puderem recorrer a capitais de terceiros irão fazê-lo. O limite será justamente o ponto em que os custos decorrentes do financial distress igualarem os benefícios tributários do endividamento. Essa evidência confirma a teoria da estrutura ótima de capital (tradeoff).

Segundo a teoria rival (pecking order), as firmas decidem baseadas em uma ordem de preferência, iniciando pela fonte interna de financiamento e só recorrendo a capitais externos quando esgotada a primeira. Nesse caso, a variável tributária não deveria explicar o endividamento, o que justificou a hipótese $H 2$, formulada para investigar as firmas que se decidiam pelo alto endividamento movidas pela dependência desses recursos para o financiamento de suas atividades, não pelo incentivo tributário.

A formulação da hipótese $H 2$, uma inovação em relação a estudos empíricos anteriores, não foi desprovida de fundamento, embora não tenha sido possível rejeitar a hipótese nula segundo a qual a relação positiva entre tributação e endividamento existiria mesmo para empresas que apresentam alto endividamento e baixo nível de tributação.

Conforme evidenciado nas Tabelas 4,5 e 6 , as variáveis dummy mostraram-se significativas e relevantes para explicar o endividamento das empresas consideradas descapitalizadas, com alto endividamento e baixa tributação.

A hipótese central da pesquisa $(H 1)$ restou confirmada: o nível de tributação do lucro da firma afeta sua decisão quanto à estrutura de capital e a relação se dá no mesmo sentido, ou seja, quanto maior a incidência tributária, maior será o endividamento. Esse achado confirma uma das principais proposições da teoria da tributação ótima (tradeoff).

Os resultados resistiram ao procedimento de validação consistente na divisão da amostra em duas partes e a realização dos testes dos modelos em relação a cada uma das partes isoladamente, comparando-se os resultados obtidos com aqueles da amostra integralmente considerada (HAIR et al., 1998; AAKER et al., 2001). 
Cabe registrar certos aspectos que limitam as conclusões que possam advir dos resultados da pesquisa:

- Não foi possível determinar as alíquotas marginais a que estavam sujeitas as firmas, que seria a proxy mais indicada para o fator tributação. Foi utilizada a alíquota média, como a maioria dos estudos anteriores.

- A amostra limita-se às 500 maiores empresas estabelecidas no Brasil, não incluindo pequenas e médias empresas.

- A criação das variáveis dummy mediante a utilização da análise cluster, apesar de evitar o viés do pesquisador, não assegura necessariamente uma correta identificação das empresas consideradas descapitalizadas, com alto endividamento e baixa tributação.

- Foram utilizados valores médios para as variáveis a partir de uma série de dados relativos a três exercícios sociais e foi realizada uma análise unicamente transversal. Tal procedimento pode produzir resultados diferentes dos que se obteria caso fossem utilizados dados de apenas um período ou, alternativamente, caso fosse utilizada uma análise cross-sectional e time-series, com dados em painel.

- O grau de concentração dos setores, utilizado como variável independente no teste de hipóteses, foi calculado com base apenas nas empresas da amostra, de modo que não foram consideradas todas as empresas que integram cada setor.

\section{CONCLUSÃO}

O presente estudo teórico-empírico propôs-se a analisar a influência da tributação do lucro sobre o endividamento das empresas no Brasil à luz das teorias da estrutura de capital. Segundo a teoria do tradeoff, a vantagem fiscal decorrente da dedutibilidade dos juros cria um incentivo ao endividamento. O limite será justamente o ponto em que os custos decorrentes de dificuldades financeiras igualarem os benefícios tributários do endividamento.

Por outro lado, sob a perspectiva da teoria da hierarquização das fontes de financiamento (pecking order), as firmas decidem baseadas em uma ordem de preferência, iniciando pela fonte interna de financiamento e só recorrendo a capitais externos quando esgotada a primeira.

A partir desse referencial teórico, foram identificadas e incluídas no modelo as demais variáveis apontadas pela literatura como impactantes da decisão de estrutura de capital das 
empresas. Utilizando valores médios dos anos de 2001 a 2003 de uma amostra das maiores empresas estabelecidas no Brasil e aplicando a análise de regressão linear múltipla, foram testadas duas hipóteses de pesquisas.

A primeira hipótese buscou verificar se há, efetivamente, relação positiva entre o nível de tributação do lucro e o grau de endividamento das empresas. Os resultados apontaram uma relevância estatística da variável tributação na explicação do endividamento, confirmando as predições da teoria do tradeoff.

A segunda hipótese, formulada a partir de predições da teoria do pecking order, buscou verificar se essa relação ocorre da mesma forma para empresas com alto endividamento e baixo nível de tributação do lucro. A expectativa era de que a ausência de incentivo fiscal ao endividamento faria com que a variável tributação do lucro não apresentasse relevância na explicação da estrutura de capital de empresas com essas características.

Essa expectativa não se confirmou: mesmo no caso de empresas consideradas descapitalizadas, com alto endividamento e baixa tributação, não foi possível descartar a existência de relação positiva entre tributação do lucro e grau de endividamento. Se, por um lado, isso representa um insucesso na tentativa de confirmar as expectativas da teoria do pecking order, por outro, representa um reforço às predições da teoria do tradeoff.

O presente estudo apresentou contribuições adicionais em relação às demais pesquisas empíricas aplicadas ao cenário brasileiro, dentre as quais pode ser destacada, primeiramente, sob o ponto de vista metodológico, uma maior depuração da amostra, com a eliminação justificada de observações capazes de distorcer os resultados. Foram retiradas da amostra empresas que apresentavam provisões de receitas de tributos sobre o lucro e das que, mesmo apurando prejuízo, registravam uma despesa com tributos sobre o lucro, pois a relação entre números dessa natureza torna-se sem sentido para explicar a carga tributária da empresa.

Ainda que admitidos com parcimônia diante da natural limitação de uma pesquisa ao universo da amostra analisada, os resultados somam-se aos de outros estudos realizados no Brasil, como os de Nakamura et al. (2004) e Zani e Ness Júnior (2000), que encontraram evidência empírica no mesmo sentido, ao mesmo tempo em que contradizem as expectativas deixadas por outros trabalhos que se debruçaram sobre o cenário pátrio, como os de Futema et al. (2009), Bastos e Nakamura (2009) e Terra (2002), cujos achados foram inconsistentes com os preconizados pela teoria do tradeoff.

Resta, por derradeiro, recomendar questões para futuras pesquisas. No campo da teoria da estrutura de capital e sua relação com a tributação, um aspecto que pode ser aperfeiçoado 
em trabalhos futuros, embora não seja tarefa fácil, é a estimação das alíquotas marginais a que estão sujeitas as firmas.

Pesquisas futuras podem ampliar a amostra para incluir pequenas e médias empresas, de modo a verificar se a escolha da estrutura de capital é impactada da mesma forma pela tributação do lucro.

Outro rumo sugerido é o estudo da questão à luz da literatura das escolhas contábeis (accounting choices) e do gerenciamento de resultados (earnings management), de modo a avaliar como as decisões de estrutura de capital no Brasil subsumem-se às análises e predições dessas doutrinas.

\section{Referências}

AAKER, D. A. et al. Pesquisa de marketing. São Paulo: Atlas, 2001.

AYERS, B. C. et al. The influence of income taxes on the use of inside and outside debt by small businesses. National Tax Journal, Washington, v. 54, n. 1, p. 27-55, Mar. 2001.

BASTOS, D. D.; NAKAMURA, W. T. Determinantes da estrutura de capital das companhias abertas no Brasil, México e Chile no período 2001-2006. Revista Contabilidade \& Finanças USP, São Paulo, v. 20, n. 50, p. 75-94, maio/ago. 2009.

BRIGHAM, E.; HOUSTON, J. F. Fundamentos da moderna administração financeira. Rio de Janeiro: Campus, 1999.

BRITO, R. D.; LIMA, M. R. A escolha da estrutura de capital sob fraca garantia legal: o caso do Brasil. FinanceLab Working Paper 08 - Ibmec, Rio de Janeiro, 2004.

BURGMAN, T. A. An empirical examination of multinational corporate capital structure. Journal of International Business Studies, Washington, v. 27, n. 3, p. 553-570, third quarter 1996.

CALEGARI, M. J. The effect of tax accounting rules on capital structure and discretionary accruals. Journal of Accounting and Economics, Rochester, v. 30, p. 1-31, 2000.

CLOYD, C. B. et al. The impact of federal taxes on the use of debt by closely held corporations. National Tax Journal, Washington, v. 50, n. 2, p. 261-277, Jun. 1997.

COELHO, A. C. D.; LOPES, A. B. Avaliaçăo da prática de gerenciamento de resultados na apuraçăo de lucro por companhias abertas Brasileiras conforme seu grau de alavancagem. Revista de Administração Contemporânea, 2a. Edição Especial, p. 121-144, 2007.

ELY, D. P. et al. Taxes and the choice of issuing preferred stock vs. debt. The Journal of the American Taxation Association, Sarasota, v. 24, n. 1, p. 29-46, Spring 2002.

EXAME MELHORES E MAIORES. São Paulo: Editora Abril, 2002. Anual. 
São Paulo: Editora Abril, 2003. Anual.

São Paulo: Editora Abril, 2004. Anual.

FERREIRA, L. S. Estrutura de capital: um teste preliminar da pecking order hypothesis. In: ENCONTRO ANUAL DA ASSOCIAÇÃO NACIONAL DOS PROGRAMAS DE PÓSGRADUAÇÃO EM ADMINISTRAÇÃ̃O - ENANPAD, 21, 1997, Rio das Pedras, Anais eletrônicos... Rio das Pedras: ANPAD, 1997.CD-ROM.

FUTEMA, M. S. et al. Estrutura de capital, dividendos e juros sobre o capital próprio: testes no Brasil. Revista Contabilidade \& Finanças - USP, São Paulo, v. 20, n. 49, p. 44-62, jan./abr. 2009.

GROPP, R. E. Local taxes and capital structure choice. International Tax and Public Finance, Boston, v. 9, n. 1, p. 51-71, Jan. 2002.

GUENTHER, D. A. Foreign tax rates and marginal benefit of interest expense for U. S. Multinationals. Journal of International Accounting, Auditing \& Taxation, Greenwich, v. 5, n. 2, p. 147-160, 1996.

HAIR JUNIOR, J. F. et al. Multivariate data analysis: with readings. 5.ed. Upper Saddle River, New Jersey: Prentice-Hall, 1998.

HARWOOD, E.; MANZON, G. B. Tax clienteles and debt maturity. The Journal of the American Taxation Association, Sarasota, v. 22, n. 2, p. 22-40, 2000.

JENSEN, M.; MECKLING, W. Theory of the firm: managerial behavior, agency costs and owernship structure. Journal of Financial Economics, Amsterdam, v. 3, p. 305-360, 1976.

JORGE, S.; ARMADA, M. J. R. Factores determinantes do endividamento: uma análise em painel. In: ENCONTRO ANUAL DA ASSOCIAÇÃO NACIONAL DOS PROGRAMAS DE PÓS-GRADUAÇÃO EM ADMINISTRAÇÃO - ENANPAD, 23, 1999, Foz do Iguaçu, Anais eletrônicos... Foz do Iguaçu: ANPAD, 1999. CD-ROM.

KAYO, E. et al. A influência dos ativos intangíveis sobre a estrutura de capital. In: ENCONTRO ANUAL DA ASSOCIAÇÃO NACIONAL DOS PROGRAMAS DE PÓSGRADUAÇÃO EM ADMINISTRAÇÃ̃O - ENANPAD, 28, 2004, Curitiba, Anais eletrônicos... Curitiba: ANPAD, 2004. CD-ROM.

KRISHNAN, S.; MOYER, C. M. Determinants of capital structure: an empirical analysis of firms in industrialized countries. Managerial Finance, Patrington, v. 22, n. 2, p. 39-55, 1996.

MARTINS, G. A. Estatística geral e aplicada. São Paulo: Atlas, 2001.

MILLS, L. F.; NEWBERRY, K. J. Do foreign multinational's tax incentives influence their U. S. income reporting and debt policy? National Tax Journal, Washington, v. 57, n. 1, p. 89107, Mar. 2004.

MOHAMAD, M. H. Capital structure in large Malaysian companies. Management International Review, v. 35, n. 2, p. 119-130, 1995. 
MYERS, S. C. Capital structure. Journal of Economic Perspectives, Nashville, v. 15, n. 2, p. 81-102, Spring 2001.

NAKAMURA, W. T. et al. Indicadores contábeis como determinantes do endividamento das empresas brasileiras. In: ENCONTRO ANUAL DA ASSOCIAÇÃO NACIONAL DOS PROGRAMAS DE PÓS-GRADUAÇÃO EM ADMINISTRAÇÃO - ENANPAD, 28, 2004, Curitiba, Anais eletrônicos... Curitiba: ANPAD, 2004. CD-ROM.

OOI, J. The determinants of capital structure: evidence on UK property companies. Journal of Property Investment \& Finance, Bradford, v. 17, n. 5, p. 464-480, 1999.

PIGA, C. A. G. Debt and firms' relationships: the Italian evidence. Review of Industrial Organization, Boston, v. 20, n. 3, p. 267-282, May 2002.

PILOTTE, E. The economic Recovery Tax Act of 1981 and corporate capital. Financial Management, Tampa, v. 19, n. 4, p. 98-107, Winter 1990.

RESENDE, M.; BOFF, H. Concentração industrial. In Economia Industrial. Rio de Janeiro: Campus, 2002.

ROSS, S.; JAFE, J. F.; WESTERFIELD, R. W. Administração financeira: corporate finance. São Paulo: Atlas, 2009.

SHIH, M. S. H. Determinants of corporate leverage: a time-series analysis using U. S. tax return data. Contemporary Accounting Research, Toronto, v. 13, n. 2, p. 487-504, 1996.

SMITH, J. K. The effect of the Tax Reform Act of 1986 on the capital structure of foreign subsidiaries. The Journal of the American Taxation Association, Sarasota, v. 19, n. 2, p. 1-18, Fall 1997.

TERRA, P. R. S. An empirical investigation on the determinants capital structure in Latin America. In: ENCONTRO ANUAL DA ASSOCIAÇÃO NACIONAL DOS PROGRAMAS DE PÓS-GRADUAÇÃO EM ADMINISTRAÇÃO - ENANPAD, 26, 2002, Salvador, Anais eletrônicos... Salvador: ANPAD, 2002. CD-ROM.

WESTON, J. F.; BRIGHAM, E. F. Fundamentos da administração financeira. 10. ed. São Paulo: Makron Books, 2000.

ZANI, J.; NESS JÚNIOR, W. L. Os juros sobre o capital próprio versus a vantagem fiscal do endividamento. In: ENCONTRO ANUAL DA ASSOCIAÇÃO NACIONAL DOS PROGRAMAS DE PÓS-GRADUAÇÃO EM ADMINISTRAÇÃO - ENANPAD, 24, 2000, Anais eletrônicos... ANPAD, 2000. CD-ROM. 